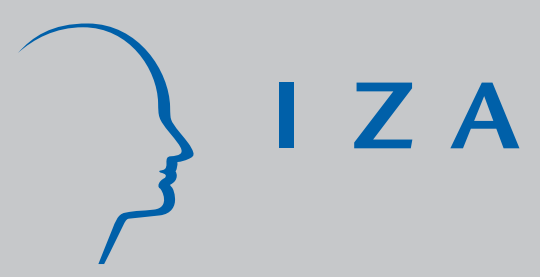

IZA DP No. 3853

Fertility and Female Employment Dynamics in Europe: The Effect of Using Alternative Econometric Modeling Assumptions

Pierre-Carl Michaud

Konstantinos Tatsiramos

November 2008 


\title{
Fertility and Female Employment Dynamics in Europe: The Effect of Using Alternative Econometric Modeling Assumptions
}

\author{
Pierre-Carl Michaud \\ RAND, Netspar and IZA \\ Konstantinos Tatsiramos
}

$I Z A$

Discussion Paper No. 3853

November 2008

IZA

P.O. Box 7240

53072 Bonn

Germany

Phone: +49-228-3894-0

Fax: +49-228-3894-180

E-mail: iza@iza.org

\begin{abstract}
Any opinions expressed here are those of the author(s) and not those of IZA. Research published in this series may include views on policy, but the institute itself takes no institutional policy positions.

The Institute for the Study of Labor (IZA) in Bonn is a local and virtual international research center and a place of communication between science, politics and business. IZA is an independent nonprofit organization supported by Deutsche Post World Net. The center is associated with the University of Bonn and offers a stimulating research environment through its international network, workshops and conferences, data service, project support, research visits and doctoral program. IZA engages in (i) original and internationally competitive research in all fields of labor economics, (ii) development of policy concepts, and (iii) dissemination of research results and concepts to the interested public.
\end{abstract}

IZA Discussion Papers often represent preliminary work and are circulated to encourage discussion. Citation of such a paper should account for its provisional character. A revised version may be available directly from the author. 
IZA Discussion Paper No. 3853

November 2008

\section{ABSTRACT \\ Fertility and Female Employment Dynamics in Europe: The Effect of Using Alternative Econometric Modeling Assumptions}

We investigate the direct and long-run effects of fertility on employment in Europe estimating dynamic models of labor supply under different assumptions regarding the exogeneity of fertility and modeling assumptions related to initial conditions, unobserved heterogeneity and serial correlation in the error terms. We find overall large direct and long-run effects of giving birth on employment probabilities, and these effects differ considerably across countries. We find that within countries the results are sensitive to the statistical assumption made on initial conditions, the inclusion of serial correlation and the assumption of strict exogeneity of children. However, the pattern across countries is robust to these assumptions. We show that such patterns are largely consistent with prevailing institutional differences related to the flexibility of the labor markets and family policies.

JEL Classification: C23, C25, D91, J22

Keywords: intertemporal labor supply, female employment, fertility, dynamic binary choice models, initial conditions

Corresponding author:

Konstantinos Tatsiramos

IZA

P.O. Box 7240

53072 Bonn

Germany

E-mail: tatsiramos@iza.org

\footnotetext{
* We thank Alpaslan Akay, Massimiliano Bratti, Deborah Cobb-Clark, Daniel Hamermesh and Arne Uhlendorff for useful comments and suggestions.
} 


\section{Introduction}

All European and other developed countries have experienced considerable changes in both female employment and fertility in the last thirty years. There is by now a large literature which investigates the effect of the increased female employment on fertility as a result of the higher opportunity cost associated with stronger labor market attachment (Becker, 1991; Cigno, 1991; Ermisch, 2003). Similarly, there is a large literature on the effect of fertility on employment (Browning, 1992), part of which has emphasized that employment and fertility decisions are the result of a dynamic process, so that the size of the effect of additional children on labor supply depends crucially on how past labor supply and existing children are accounted for (Nakamura and Nakamura, 1985; Carrasco 2001). This suggests that it is important to understand how modeling assumption might affect the dynamic effect of children on employment.

The purpose of this paper is to investigate the dynamics of fertility and female employment across a number of European countries focusing on the direct and long-run effects of births on employment dynamics. The analysis in this paper has two novel and important features. The first is that we compare the motherhood effect under different assumptions regarding the exogeneity of fertility and other econometric modeling assumptions. We do so by using dynamic binary choice models of labor supply that distinguish the direct effect of fertility on employment from persistence due to unobserved heterogeneity or state-dependence. In particular, we first estimate a dynamic binary choice equation for employment assuming fertility as strictly exogenous. Under the same exogeneity assumption, we provide sensitivity analysis with respect to the way initial conditions and unobserved heterogeneity are modeled and the presence of serial correlation in the error term. We then relax the exogeneity assumption and estimate a bivariate dynamic model of employment and fertility decisions using as an instrument the sex composition 
of children in families with two or more children. This joint estimation allows for feedback effects from employment on fertility. The second is that we extend the analysis to a number of countries which differ in the institutions facilitating the combination of work and motherhood (e.g. child related policies and flexible labor markets). The set of countries considered represent the range of institutional regimes which prevail in Europe. Understanding the dynamic effect of children on employment is relevant from an economic point of view since a large absence from employment due to motherhood may have consequences for long-term career outcomes (Albrecht et al., 1999; Herr, 2007). In addition, large and persistent motherhood effects on employment might affect the overall target of increasing the employment of older workers, which in turn has consequences for the sustainability of the pension systems.

We find considerably large direct and long-run effects of giving birth on employment probabilities, and these effects differ considerably across countries. We find that within countries the results are sensitive to the statistical assumption made on initial conditions, the inclusion of serial correlation, and the assumption of strict exogeneity of children. In particular, the assumption of serially independent errors and strictly exogenous children tend to lead to lower estimates of births on employment. We find that estimates of state-dependence in employment are affected by the assumption made regarding initial conditions but not the direct birth effects. Despite the sensitivity to these assumptions, the pattern of direct and long-run effects of a birth is relatively robust across countries. We show that such patterns are largely consistent with prevailing institutional differences related to the flexibility of the labor markets and family policies.

Section 2 presents the data used in the analysis, describes the four institutional regimes and offers some descriptive figures on employment and fertility outcomes across countries. Section 3 
presents the empirical approach used. In section 4 we present the results, perform robustness checks and investigate the simulated response to a birth in the set of countries considered. A discussion on how to relate the findings with the prevailing institutional differences across countries is also provided. We finally conclude in section 5.

\section{The Data}

The analysis is based on individual data from the European Community Household Panel (ECHP, 1994-2001). The ECHP is a survey based on a standardized questionnaire that involves the annual interviewing of a representative panel of households and individuals in each country, covering a wide range of topics including demographics, employment characteristics, education etc. In the first wave a sample of some 60,500 nationally represented households approximately 130,000 adults aged 16 years and over - were interviewed in the then 12 Member States. There are three characteristics which make the ECHP relevant for this study: the simultaneous coverage of employment status, the standardized methodology and procedures yielding comparable information across countries; and the longitudinal design in which information on the same set of households and persons is gathered.

\subsection{Institutional Regimes}

We focus the analysis on seven European countries: Denmark, France, Germany, Italy, the Netherlands, Spain and the U.K. These countries differ in terms of institutions related to employment and childcare, and represent the different regimes (Esping-Andersen, 1990) that prevail in Europe (the Nordic, the Continental, the Anglo-Saxon and the Mediterranean). In particular, Denmark belongs to the Nordic regime, which is characterized by flexible labor markets and generous welfare policies (flexicurity). These policies are financed by relatively 
high taxes on labor income and/or social security contributions. In the Continental regime, characterized by Germany, France and the Netherlands, social transfers are related to previous earnings, and means-tested social transfers act as a residual safety net. The U.K. belongs to the Anglo-Saxon regime, which consists of relatively flexible labor markets as well as means-tested social transfers, which are often less generous than in other regimes. These are financed with lower income taxes and social security contributions compared to the universal and the conservative welfare regimes. In the Mediterranean countries (Italy and Spain) the prevailing institutional regime relies on family ties rather than on social insurance.

Differences in childcare institutions and child benefit policies are potentially associated with the variation in the effect of motherhood on employment. Table 1 presents the main institutional features which prevail across countries during the period analyzed. Denmark has the longest duration of maternity leave and the highest childcare coverage, particularly for children younger than three years old. France has also high childcare coverage for younger children. For the remaining countries, childcare coverage for children younger than three years old is quite low. Childcare provision for children older than 3 is extensively available in all countries. Denmark provides the highest coverage while the U.K. provides the lowest.

\subsection{Sample}

We construct an unbalanced panel of all married and cohabiting women (referred to as married in what follows) aged between 20 and 45 years old (in the first observed wave), who are continuously observed for at least three waves. ${ }^{2}$ We exclude those women who are still at school

\footnotetext{
${ }^{2}$ We select married or cohabiting females to avoid dealing with changes in marital status. A similar selection criterion is applied in other studies (e.g. Hyslop, 1999).
} 
or retired. ${ }^{3}$ Employment is defined as working for more than 15 hours per week. Although there are many relevant dimensions regarding labor supply one could look at (extensive vs. intensive margin, different hours cut-off), we use this definition because it measures a more solid attachment to the labor force than a definition which uses a lower cut-off (say any positive hours). Table 2 provides summary statistics of the main characteristics of women in each country. The sample size varies from 1,075 women in Denmark to 2,699 in Italy. The average employment rate over the sample period is the lowest in Italy and Spain (48.5\% and 38.8\%) and the highest in Denmark (about 83.6\%) followed by the U.K. and France, Germany and the Netherlands.

The relationship between the number of children and employment is shown at the bottom of Table 2. Women without children have higher employment rates in all countries. One exception is Denmark, where there is no significant difference. Overall, employment rates decrease with the number of children. It is worth noting that even in the absence of children, the average employment rate for women in Italy and Spain is significantly lower compared to the rest of the countries. In order to obtain a measure of the effect of a birth on employment, we follow the employment patterns around the time of the birth of women who have a new child. We select only women who do not have subsequent births. We present the employment rates relative to the pre-birth employment rate in Table 3. Except for Germany, the employment rate first drops at the time of the birth. The highest drop in employment is observed for France and the Netherlands followed by the U.K. and Denmark. For Italy and Spain the employment drop is smaller. There is variation in the persistence of the drop. The drop, for example, is relatively persistent in Italy, while employment seems to recover faster in other countries. These

\footnotetext{
${ }^{3}$ The fraction of married or cohabiting respondents still in school between the ages of 20 to 30 does not vary substantially across countries.
} 
descriptive statistics are difficult to interpret for various reasons. The persistence of the drop can be due to several factors, including state-dependence in employment (it is difficult to find a job upon exiting) or the financial and time burden of having young children.

\section{Empirical Strategy}

\subsection{Theoretical Motivation}

There is a large literature on the effect of fertility on employment (Browning, 1992). Earlier studies considered the static relationship between the number of children in a household and employment (e.g. Mincer, 1962). Many authors have emphasized that employment and fertility decisions are the result of a dynamic process and evidence points to the fact that the size of the effect of children on labor supply depends crucially on how past labor supply and children are accounted for (Nakamura and Nakamura, 1985). From a life-cycle perspective, current decisions depend in part on past decisions which determine opportunities and expectations about future outcomes. Current employment is likely to depend on the number of children in the household which is the result of past fertility decisions. Similarly, the decision to have a child may depend on current employment. For those holding a job, the prospect of incurring large costs upon returning may lead them to stay in the labor force and avoid having children in the first place (Garibaldi and Wasmer, 2004).

As argued by Keane and Wolpin (2002), the solution to a life-cycle model of employment and fertility behaviour will generally take the form of Markov decision rules, such that flexible dynamic reduced form models are good approximations to the predicted behaviour from the life-cycle models. For example, Hyslop (1999) derives from a stylized life-cycle model a dynamic binary employment equation which is consistent with life-cycle optimization. 
However, the statistical assumptions made when postulating such dynamic reduced-form models imply restrictions on behavior which, if violated, will lead to an erroneous interpretation of the results. As noted before by others (e.g. Carrasco, 2001), the assumption of strict exogeneity of birth in an employment equation rules out feedback effects from employment to fertility. Few life-cycle models would rule out feedback effects. In general, employment affects current and future returns in the labor market and thus affects current and future budget constraints.

Similarly, statistical assumptions on the error structure of the employment equation are important whether or not such errors are correlated with birth outcomes. A serially independent error structure is inconsistent with at least two phenomena: unobserved heterogeneity and serial correlation due to differences in opportunities or taste for work. Even if uncorrelated with the birth outcomes, such serial correlation will lead to biases in employment dynamics, which will then bias the effect of children on employment. When correlated with the presence of children, perhaps due to heterogeneity in preferences, such unobserved heterogeneity leads to a classical omitted variables bias in the estimate of the effect of children on employment.

We tackle each of these issues in turn. We first present an econometric model of employment dynamics which assumes children are exogenous. In this model, we focus on assumptions regarding the error structure of the employment equation. The model is similar to Hyslop (1999). We then allow children to be predetermined as in Carrasco (2001). We postulate a similar dynamic equation for births which allows for feedback as well as using the gender mix of existing children to identify the effect of a birth on employment. 


\subsection{Econometric Model}

We define an indicator $y_{i t}$ if the respondent denoted by $i=1 \ldots N$ reports being employed $(=1$, else 0 ) in year $t$. We observe this employment indicator, an indicator which records a birth since the last interview $\left(b_{i t}\right)$, the number of children at the last interview $k_{i t}$, and other relevant characteristics $X_{i t}$ for $T_{i}$ consecutive years. We specify the decision rule as

$$
y_{i t}=I\left(x_{i t} \beta+\varphi_{b} b_{i t}+\varphi_{k} k_{i t}+\gamma y_{i t-1}+u_{i t}>0\right), \quad t=1, \ldots, T_{i}-1 .
$$

The unobservable term $u_{i t}$ is decomposed into a time-invariant term $\alpha_{i}$, and a time-variant term $\varepsilon_{i t}$. We first assume that $\left(x_{i t}, k_{i t}, b_{i t}\right)$ are strictly exogenous with respect to this unobservable $\varepsilon_{i t}$

(conditional on $\alpha_{i}$ ). This assumption rules out any feedback effect from employment to future births. We allow for different effects on the "stock" of children aged 1-3, 4-6, 7-12 and 13-18, as in Hyslop (1999). Hence, $k_{i t}$ is a vector.

The parameter $\gamma$ captures true state-dependence (Heckman and Willis, 1977). In contrast, the presence of time invariant unobserved heterogeneity creates persistence because of selfselection of those with high employability in employment and those with low employability in non-employment. Hence, without taking into account $\alpha_{i}$, differences in employment rates are observed conditional on the previous employment status. This occurs without a causal effect of employment state on future employment.

\section{Unobserved Heterogeneity}

The individual specific term $\alpha_{i}$ may be correlated with the number of children in the household. Women might decide to have children because they have few career prospects. They may also decide to have children because they have other family members who can provide informal 
childcare if they work. The same endogeneity problem probably holds true for the inclusion of the husband's income as a measure of non-labor income, which could be correlated with unobserved heterogeneity due for example to assortative mating.

There are different ways to address this either in a fixed effect or a random effect framework. Allowing for fixed effects, two estimators have been proposed. The first one by Honoré and Kyriazidou (2000) imposes strong requirements on the distribution of the covariates. In particular, it rules out age or time dummies, and its rate of convergence is lower than $N^{-1 / 2}$. Carro (2007) recently proposed a modified maximum likelihood estimator that reduces the bias of the maximum likelihood estimator but does not eliminate it.

In this paper we focus on random effect approaches. The random effect assumption has two main caveats: 1) it requires independence of the regressors with the random effect, and 2) it generally requires a distributional assumption. However, these two caveats can be partially addressed. We address the first following Mundlack (1978) who proposed using a quasi-fixed effect approach. Similarly to Hyslop (1999), we adopt the following specification for unobserved heterogeneity

$$
\alpha_{i}=\sum_{s=0} \delta_{s} k_{i s}+\sum_{s=0} \vartheta_{s} m_{i s}+\eta_{i},
$$

where $k_{i s}$ and $m_{i s}$ are the number of children and non-labor income in period $s$, respectively. The remaining unobservable $\eta_{i}$ is assumed to be independent of $k_{i s}$ and $m_{i s}$ and other regressors in $x$. The effects for births, the number of children, and non-labor income are, by construction, independent of $\eta_{i}$. However, this quasi-fixed effect strategy has the disadvantage of requiring a balanced panel $\left(T_{i}=T\right)$. Hence, we do not consider this specification as our base specification. 
We will test for the presence of quasi-fixed effects restricting our sample to the balanced panel and compare estimates.

We can also relax the second assumption inherent in the random effect approach. We do not impose any distributional assumptions on the remaining unobserved heterogeneity $\eta_{i}$. Instead, we use the point-mass approach suggested by Heckman and Singer (1984). We assume that the distribution of $\eta_{i}$ has $K$ points of support: $\eta_{k}, k=1, \ldots, K$ with associated mass probability $p_{k}=\operatorname{Pr}\left(\eta_{i}=\eta_{k}\right)$.

As for the time-varying unobservables $\varepsilon_{i t}$, we assume that they are serially correlated with serial correlation parameter $\rho: \varepsilon_{i t}=\rho \varepsilon_{i t-1}+\sigma v_{i t}, v_{i t} \sim N(0,1)$ and we fix $\sigma=1$ for the identification of the scale.

\section{Initial Conditions}

For $\gamma$ different than zero and if unobserved heterogeneity is present, direct estimation of equation (1) suffers from an initial condition problem. Since the whole history of $y$ is not observed, the initial observation $y_{i 0}$ is potentially correlated with $\eta_{i}$ such that integrating over the marginal distribution of this heterogeneity term will yield inconsistent estimates. This is known as the initial condition problem (Heckman, 1981). The probability we wish to compute is

$$
\operatorname{Pr}\left(y_{i 1}, . ., y_{i T-1} \mid z_{i}\right)=\int \operatorname{Pr}\left(y_{i 1}, . ., y_{i T-1} \mid z_{i}, \eta_{i}, y_{i 0}\right) d F\left(\eta_{i}, y_{i 0} \mid z_{i}\right)
$$

However, we lack information on the joint distribution of $\eta_{i}$ and $y_{i 0}, F\left(\eta_{i}, y_{i 0} \mid z_{i}\right)$, where $z_{i}$ is the vector of all regressors in all time periods. The most widely used "solution" is proposed by Heckman (1981). We can decompose $F\left(\eta_{i}, y_{i 0} \mid z_{i}\right)$ as the product of a conditional probability $\operatorname{Pr}\left(y_{i 0} \mid z_{i}, \eta_{i}\right)$ and the marginal probability for $\eta_{i}$. 
The conditional probability can be specified as a "reduced-form" solution substituting backward,

$$
\operatorname{Pr}\left(y_{i 0} \mid z_{i 0}, \eta_{i}\right)
$$

where this equation does not share parameters with the first equation but includes $\eta_{i}$ (and $y_{i 0}$ ). In particular, one can assume

$$
y_{i 0}=I\left(z_{i 0} \beta_{0}+\lambda \eta_{i}+\varepsilon_{i 0}>0\right),
$$

where $\operatorname{var}\left(\varepsilon_{i 0}\right)=1$ for identification of scale. The initial condition equation is informative for the estimation of the dynamic equation because of the presence of $\eta_{i}$. The last step is to integrate over the marginal distribution of $\eta_{i}$. The integrand $\operatorname{Pr}\left(y_{i 1}, . ., y_{i T-1} \mid z_{i}, \eta_{i}, y_{i 0}\right)$ in (3) is simulated using the Geweke-Hajivassiliou-Keane (GHK) simulator, which is known to perform well for this type of model (Hajivassiliou et al., 1996). The covariance matrix of $\varepsilon_{i t}$ is easily derived since $E\left(\varepsilon_{i t} \varepsilon_{i s}\right)=\frac{\rho^{k-s} \mid}{1-\rho^{2}}$ due to the $\operatorname{AR}(1)$ assumption.

An alternative to the Heckman solution is proposed by Wooldridge (2005), who assumes instead in (3) that $E\left(\eta_{i} \mid y_{i 0}, z_{i}\right)=\psi y_{i 0}$ in the quasi-fixed effect setting we have already adopted. ${ }^{4}$ Since the number of children in the first period may also be correlated with $\eta_{i}$ we also condition on the initial number of children as suggested by Wooldridge (2000). This conditional likelihood approach does not appear to impose stronger assumptions than assumed in (5). Hence, another approach is to simply include in the latent index in (1) an additional term in $y_{i 0}$ and directly compute (3). Since no method has a clear advantage over the other, we will apply both and

\footnotetext{
${ }^{4}$ In the quasi-fixed approach, with a balanced panel, we have already conditioned on the path of exogeneous variables.
} 
compare the resulting estimates in terms of average partial effects. ${ }^{5}$ Both models are estimated using maximum likelihood (BFGS numerical optimization) and standard errors are computed using the sandwich estimator.

\section{Endogeneity of Fertility}

As noted earlier, a key assumption made is that children are strictly exogenous in the employment equation which rules out feedback effects. We relax this assumption following the strategy proposed by Carrasco (2001). ${ }^{6}$ We specify a dynamic process for birth which depends on lag employment and the number of existing children. To deal with simultaneity we use the presence of children of the same sex as an instrument for the effect of a birth on employment. Angrist and Evans (1998) proposed this instrument and argued that parents with 2 children of the same sex are more likely to have a third one. Table 4 shows some summary statistics with respect to the number of children in the sample. In all countries less than half of the women have two or more children, with the percentage of children being of the same sex varying from $17.6 \%$ in the U.K. to 22.2\% in France. Within those who have children of the same sex, the share of children who are boys is not different from the share of children who are girls. Table 5 shows that based on a pooled probit estimation using the ECHP data the same sex indicator $s_{i t-1}$ (1 if same sex, 0 if not) is predictive of $3^{\text {rd }}$ or higher births in all countries. The instrument is only defined for women with two or more pre-existing children. We assume it takes value zero when the number of children is 1 or zero. However, this means that the instrument conveys information on the total number of children, and if the effect of existing children on employment is non-linear, this could invalidate the orthogonality condition required for identification. Hence,

\footnotetext{
${ }^{5}$ See Chay and Hyslop (2001) for a comparison of other initial condition solution methods not considered here.

${ }^{6}$ Other studies have modeled jointly fertility and employment using various identifying assumptions, e.g. Hotz and Miller (1988), Francesconi (2002), Del Boca and Sauer (2008).
} 
in both employment and birth equations, we also include an indicator which equals one if the number of children is less than 2 .

We assume a dynamic process of the form

$$
b_{i t}=I\left(x_{i t} \zeta+\delta_{y} y_{i t-1}+\delta_{k} k_{i t}+\pi s_{i t-1}+\mu_{i}+\omega_{i t}>0\right), t=1, \ldots, T-1
$$

where $\mu_{i}$ is an unobserved heterogeneity term and $\omega_{i t}$ is a serially correlated shock defined as $\omega_{i t}=\rho_{b} \omega_{i t-1}+\xi_{i t}, \xi_{i t} \sim N(0,1)$. The pair $\left(\eta_{i}, \mu_{i}\right)$ is allowed to be correlated and we specify a two dimensional mass-point distribution for these terms. We also allow $\left(\xi_{i t}, v_{i t}\right)$ to be correlated with correlation coefficient $\rho_{v}$.

The system composed of equation (1) and (6) suffers from an initial condition problem. We follow Alessie et al. (2004) and adopt a Heckman-type initial condition solution. We specify the initial conditions as

$$
\begin{aligned}
& y_{i 0}=I\left(z_{i 0} \beta_{0}+\lambda_{y y} \eta_{i}+\lambda_{y b} \mu_{i}+\varepsilon_{i 0}>0\right) \\
& k_{i 0}=I\left(z_{i 0} \zeta_{0}+\lambda_{b y} \eta_{i}+\lambda_{b b} \mu_{i}+\omega_{i 0}>0\right)
\end{aligned}
$$

and assume $\left(\varepsilon_{i 0}, \omega_{i 0}\right)$ are jointly normal with correlation coefficient $\rho_{0}$. Together with (1) and (6), this forms a system of dynamic binary choice equations. These are estimated jointly as in Alessie et al. (2004). The only difference is that we use a point mass approach. This means that we simulate choice probabilities for each mass-point type and then weight those simulated probabilities to form the likelihood. 


\section{Results}

We present first the estimates of the employment equation based on the dynamic binary choice model which assumes fertility is exogenous. We also discuss the sensitivity of the results to various assumptions (initial conditions, serial correlation, quasi-fixed effects). We then present the estimates of a bivariate dynamic binary choice model on the employment and fertility decisions, which allows fertility to be endogenously determined.

\subsection{Employment Dynamics with Strictly Exogenous Fertility}

Table 6 presents average partial effects from our base specification. The model is estimated using the Heckman initial conditions solution and allowing for serial correlation in the error term.

Inspection of the direct birth effects reveals considerable differences across countries. For countries such as the Netherlands, France and the U.K. giving birth to a child has the largest effect: lowering the employment rate by roughly 27 percentage points (p.p.), 30 p.p. and 37 p.p., respectively. The contemporaneous effect of a birth in Denmark and Spain is much lower (about 16 p.p.) and relatively small in Italy (8.5 p.p.). For Germany the direct birth effect is very small but the "stock" effect of children aged 0-3 is the largest (31 p.p.). This delayed effect of a birth on employment is consistent with the descriptive analysis shown in Table 3 and might be related to women being considered as employed during the first year of their maternity leave. The "stock" effect of young children (aged 1-3) is much smaller (between 12 p.p.-16 p.p.) in the countries which experience the largest direct birth effect (Netherlands, France and U.K.); and it 
is even lower for Italy and Spain, and very small for Denmark. Finally, as children grow older the effect on employment decreases in all countries.

The dynamic effect of fertility cannot be evaluated without looking at the state-dependence effect which works as a potential multiplier for any direct effect of covariates on employment probabilities. As discussed in the previous section, any observed persistence in employment rates can be the result of either true state-dependence or spurious correlation due to persistent unobserved heterogeneity. The observed persistence of the birth effect might be also linked to labor market rigidities, such as search frictions or to human capital depreciation, which create persistence in employment outcomes. Hence, it may be that the persistence is not due to the lasting effect of having children but rather due to search frictions which make return to work more difficult. Even if the contemporaneous birth effect is small, search frictions may have a feedback effect on employment, which creates persistence. Disentangling the two potential sources of persistence is important in understanding the role of births and its sensitivity to institutional differences across countries.

Table 6 shows that state-dependence is highest in the Netherlands and the U.K., followed by France and Italy, while Germany, Denmark and Spain exhibit the lowest state-dependence effects. It is interesting that the countries with the highest direct birth effects have also the highest state-dependence effects.

As for the effect of other characteristics, the more educated the women the more significantly likely they are to be employed. The difference in employment rates across education levels (the education "gradient") is higher in Italy and Spain; countries where female participation is low over this period. This suggests that in the Mediterranean countries it is the highly skilled women who are more likely to participate in the labor market conditional on 
fertility. In most countries, except in Denmark and the U.K., we find that labor supply behavior of women is negatively related to our measure of permanent non-labor income. Based on the discussion in Section 3, it is difficult to say if this rejection is due to a correlation in preferences or other factors, or due to a true causal effect of permanent income. Panel data is silent on this possibility since permanent income, by definition, does not vary over time.

\subsection{Sensitivity Analysis}

We investigate the sensitivity of our findings to the way initial conditions are modeled, the assumption of serially correlated errors and the presence of quasi-fixed effects. Table 7 shows the average partial effects of the main variables of interest - the birth effect, the "stock" of children and state-dependence - from the dynamic model which relaxes one of these assumptions at the time.

Starting with the initial conditions solution, the top panel of Table 7 shows that using the Wooldridge solution does not affect the direct effect of birth and the effect of the "stock" of children compared to the Heckman initial conditions solution. The effect of state-dependence is, however, different between the methods with the one using the Wooldridge method, producing lower state-dependence effects in all countries. The ranking though is not altered significantly with the Netherlands France and the U.K. still being ranked higher than Germany, Spain and Denmark. The estimated effect for Italy does not seem to be very sensitive to the way initial conditions are treated, which alters its ranking as the effect for the other countries drops substantially more. Turning to the assumption of no serially correlated errors in the second panel of Table 7, the results suggest that ignoring serial correlation leads to somewhat lower direct effects and significantly lower state dependence effects, although the ranking of countries is 
again not affected. That is, ignoring serial correlation leads to a downward bias for the effects of interest. Likelihood ratio tests reject the null hypothesis of no serial correlation. We have also estimated our base model on a balanced panel where we introduced quasi-fixed effects to relax the independence assumption of children with random effects. This turns out to have little effect on our results: the main qualitative finding with respect to the ranking of the birth effect and the state dependence remain the same. However, a likelihood ratio test that the $\delta_{s}$ from equation (2) were jointly zero is rejected, which suggests that exogeneity of children is rejected. ${ }^{7}$

\subsection{Employment Dynamics with Endogenous Fertility}

The analysis so far assumed fertility as strictly exogenous, which might lead to downward biased birth effects (Carrasco, 2001). If this is then the case, the relatively lower birth effects found in the South European countries, which might be of a surprise given the lack of sufficient childcare policies, might be explained by the bias under the exogeneity assumption. To relax this assumption we estimate the bivariate model of employment and fertility as described in section 3.2, and we present the average partial effects in Table 8.

Considering first the employment equation, the findings in the first panel of Table 8 suggest that ignoring the endogeneity of fertility leads to downward biased estimates. The direct birth effect is significantly higher in all countries, although the ranking still remains unchanged. That is, the largest negative effects are observed for the Netherlands, France and the U.K. The

\footnotetext{
${ }^{7}$ We also assessed the sensitivity of the results to various other assumptions. These results are presented in Table A1 in the Appendix. We considered whether the results were sensitive to the number of points of support used for unobserved heterogeneity. We re-estimated the models with 2-points. Overall, the estimate of state-dependence goes up as we are less able to control for unobserved heterogeneity with only two points. The Akaike information criterion (AIC) is minimized at 3 points of support for all countries. We also consider the effect of assuming a particular distribution for unobserved heterogeneity. We assumed the distribution to be normal. This had only a small effect on the results. We reached a similar conclusion when increasing the number of Halton draws used to simulate multivariate probabilities from 25 to 50 (GHK simulator).
} 
effect of the number of young children aged 1-3 is also important, although to a smaller extent. For Germany, similarly to the case with exogenous fertility, the "stock" effect is the largest among all the countries. The state-dependence effect is estimated to be lower in all countries compared to the exogenous fertility case of Table 6.

In the birth equation in the second panel of Table 8, we allow for an effect of lagged employment status, which suggests in most countries a postponement effect on fertility. This effect is significant in France, Italy, Spain, Germany and the U.K. ${ }^{8}$ The distinctive feature between these countries is that conditional on lagged employment status, which produces the postponement effect, the "stock" of young children is associated with a higher probability of giving birth in Germany and the U.K., while it is associated with a lower birth probability in Italy and Spain. There seems to be a "catch-up" effect in the former countries, although in the Southern European countries the initial postponement effect due to lagged employment seems to affect subsequent birth and thus total fertility. This is in line with findings of a delay in childbearing for employed women, and, as a consequence, a postponement of subsequent births in the Mediterranean countries (Bratti and Tatsiramos, 2008). Furthermore, the same sex dummy is positively related to giving births and is significant in France, Italy and Germany, while it is less precisely estimated for the other countries. The gender of existing children in the family does not seem to play any role in the fertility decisions, which is in line with Carrasco (2001).

\subsection{Simulations}

To gauge the effects, we perform two simulation exercises using estimates from the bivariate model. First, we estimate the effect on employment of having a child taking into account

\footnotetext{
${ }^{8}$ This negative feedback of being employed last period on current birth explains the downward bias on the birth effect when fertility is assumed to be exogenous.
} 
dynamic employment and birth effects. For each country we consider a woman with average characteristics at age 20 and simulate employment outcomes until she reaches age 25 (we assume she does not have children until reaching 25). We then exogenously impose a birth at age 25 . We then follow her employment and birth outcomes until she reaches age 50. We repeat this simulation 1000 times averaging over draws of heterogeneity and time-varying shocks. Using the same draws, we estimate the counterfactual where a birth does not occur until after age 25 . In other words, we only allow for endogenous fertility outcomes after age 25 .

Figure 1 shows the relative probability of working given birth at age 25 across countries. The birth effect in relative terms is high although there appear to be some differences across countries. In particular, Germany and the U.K. exhibit the largest effects, while Denmark and Italy the lowest. The recovery in terms of employment is also quite different. In some countries (e.g. Germany, France and the Netherlands) the effect of the first birth does not vanish until women reach the age of 40 , while in the U.K. the recovery is faster despite a large initial effect. Because the effects cumulate, we also estimate the total effect of birth on years worked in the labor market. Figure 2 shows the average number of years worked in the labor market at age 50 under the two scenarios. The total effect is non-trivial and exhibits significant differences across countries. For example, it is much larger in Germany (2 years) than in the U.K. (1 year) despite the fact that the two countries have similar initial responses to the birth effects until the child reaches the age of 3. The effect in the Netherlands, France and the U.K. are similar (about 1 year), while there is almost no effect in Denmark despite some contemporaneous effect of birth on employment. The same occurs in Italy. 


\subsection{Discussion}

To interpret the findings for the dynamic effect of birth on employment across countries we refer to the institutional differences that we discussed in section 2. For countries that belong to the Nordic regime, such as Denmark, with flexible labor markets and high availability of childcare even for young children aged 1-3, we find that there is a moderate direct birth effect that does not persist over time, as women in Denmark face the lowest state-dependence effect. That is, due to labor market flexibility the penalty for exiting the labor market for having given birth is small. This is confirmed both in Figure 1 and 2, where we observe a very quick recovery of employment after birth without any cumulative effect on the total number of years worked. In contrast, in the Anglo-Saxon regime (U.K.) with relatively flexible labor markets, but with means-tested benefits and limited child-care provision, women face one of the highest direct effects of birth on employment. Due to the relative flexibility of the labor market, however, this large direct effect does not result in a long-term penalty in terms of total years worked. The recovery period in the U.K. in Figure 1 is the fastest among those countries with a large direct effect of birth. In the countries of the Continental regime (France, Germany and the Netherlands), which are placed in-between the Nordic and the Anglo-Saxon countries in terms of social security and childcare policies, women exhibit both large direct birth effects that are also persistent over time. Finally, for the Mediterranean countries (Italy and Spain) we observe the lowest direct birth effects among all countries. This could be explained by the reliance on family ties where informal childcare is provided. The evidence points to the possibility that employed women in the absence of flexible labor markets do not exit employment once having given birth to a new child. The drawback of this family based provision of childcare is that the total fertility rate might be affected. Our findings suggest that in the South European countries women 
postpone fertility while employed, and once they have young children they are less likely to have further births. This is in contrast to countries such as Germany and the U.K,. in which the initial postponement effect of fertility due to the career motive is followed by a "catch-up" effect where women experience subsequent births even in the presence of young children.

\section{Conclusion}

The goal of this paper is to investigate the dynamics of fertility and female employment across a number of European countries, focusing on the direct and long-run effects of births on employment dynamics. We find that these effects are large and differ across countries. We assessed the sensitivity of such effects to a number of modeling assumptions including initial conditions, serial correlation and strict exogeneity of children. In particular, the assumption of serially independent errors and strictly exogenous children tend to lead to lower estimates of births on employment. We find that estimates of state-dependence in employment are affected by the assumption made regarding initial conditions but not the direct birth effects. Despite being sensitive to these assumptions, results suggest a consistent pattern which is in-line with existing institutions prevailing across countries. In some countries, such as Germany and the Netherlands, we show that a birth has a substantial impact on total labor market experience at age 50, despite witnessing sometimes large exits from the labor force at the time of the birth. In others, such as Denmark, we show that the total impact on employment is small despite the fact that women exit the labor force in large numbers when they have children. These career interruptions can have a damaging impact on life-time earnings but also on well-being in old age since most countries have earnings-related pension schemes. An important avenue for future research is to quantify the financial consequences of such career-interruptions on earnings, pensions and savings. 


\section{References}

Albrecht J. W., Edin P. A., Sundström M. and Vroman S. B. 1999, 'Career Interruptions and Subsequent Earnings: A Reexamination Using Swedish Data', Journal of Human Resources, vol. 34, no. 2, pp. 49-52.

Alessie, R., Hochguertel, S. and van Soest, A. 2004, 'Ownership of Stocks and Mutual Funds: A Panel Data Analysis', The Review of Economics and Statistics, vol. 86, no. 3, pp. 783-796.

Angrist, J.D. and Evans, W.N. 1998, 'Children and Their Parents’ Labor Supply: Evidence From Exogenous Variation in Family Size’, American Economic Review, vol. 88, no. 3, pp. 450477.

Becker, G. 1991, A Treatise on the Family., Harvard University Press, Cambridge.

Bratti, M. and Tatsiramos K. 2008, 'Explaining How Delayed Motherhood Affects Fertility Dynamics in Europe’, Manuscript, IZA, Bonn.

Browning, M. 1992, 'Children and Household Economic Behavior', Journal of Economic Literature, vol. 30, no. 3, pp. 1434-1475.

Carrasco, R. 2001, 'Binary Choice With Binary Endogenous Regressors in Panel Data: Estimating the Effect of Fertility in Female Labor Participation', Journal of Business and Economic Statistics, vol. 19, pp. 385-394.

Carro, J. M. 2007, 'Estimating Dynamic Panel Data Discrete Choice Models with Fixed Effects', Journal of Econometrics, vol. 140, no. 2, pp. 503-528.

Chay, K. Y. and Hyslop, D. R. 2001, 'Identification and Estimation of Dynamic Binary Response Panel Data Models: Empirical Evidence using Alternative Approaches’ Manuscript, University of California, Berkeley.

Cigno, A. 1991, Economics of the Family, Oxford University Press.

Del Boca, D. and Sauer, R. M. 2008. 'Life Cycle Employment and Fertility Across Institutional

Environments', European Economic Review (in press).

Ermisch, J. F. 2003, An Economic Analysis of the Family, Princeton University Press.

Esping-Andersen, G. 1990. The Three Worlds of Welfare Capitalism, Princeton University Press, Princeton.

Francesconi, M. 2002, ‘A Joint Dynamic Model of Fertility and Work of Married Women’, Journal of Labor Economics, vol. 20, no. 2, pp. 336-380.

Garibaldi, P., and Wasmer, E. 2004, 'Raising Female Employment: Reflexions and Policy Tools', Journal of the European Economic Association, vol. 2, pp. 320-330.

Hajivassiliou, V., McFadden D. and Ruud, P. 1996, 'Simulation of Multivariate Normal Rectangle Probabilities and their Derivatives: Theoretical and Computational Results', Journal of Econometrics, vol. 72, no. 1-2, pp. 85-134.

Heckman, J.J. and Singer, B. 1984, 'A Method for Minimizing the Impact of Distributional Assumptions in Econometric Models for Duration Data’, Econometrica, vol. 52, no.2, pp. 271-320.

Heckman, J.J. 1981, 'The Incidental Parameters Problem and the Problem of Initial Condition in Estimating a Discrete-Time Data Stochastic Process’ in Structural Analysis of Discrete Data with Econometric Applications, Manski, C.F. and McFadden, D. (eds), MIT, Cambridge, MA.

Heckman, J.J. and Willis, R. J. 1977, ‘A Beta-Logistic Model for the Analysis of Sequential Labor Force Participation by Married Women’, Journal of Political Economy, vol. 85, no.1, p.p 27-58. 
Herr, J.L. (2007): "Does it Pay to Delay: Understanding the Effect of First Birth Timing on Women’s Wage Growth”, mimeo Berkeley

Honoré, B.E. and Kyriazidou, E. 2000, 'Panel Data Discrete Choice Models with Lagged Dependent Variables’ Econometrica, vol. 68, no. 4, pp. 839-874.

Hotz, V.J. and Miller, R.A. 1988, 'An Empirical Analysis of Life Cycle Fertility and Female Labor Supply’, Econometrica, vol. 56, no. 1, pp. 91-118.

Hyslop, D. R. 1999, 'State Dependence, Serial Correlation and Heterogeneity in Intertemporal Labor Supply Participation of Married Women. Econometrica, vol. 67, no. 6, pp. 12551294.

Keane, M. P. and Wolpin, K. I. 2002, 'Estimating Welfare Effects Consistent with Forward Looking Behavior II: Empirical Results. Journal of Human Resources, vol. 37, no. 3, pp. 600-622.

Mincer, J. 1962, 'Labor Force Participation of Married Females: A Study of Labor Supply’ in Aspects of Labor Economics, H. G. Lewis (ed), Princeton U. Press, Princeton, pp. 63-97.

Mundlack, Y. 1978. 'On the Pooling of Time Series and Cross Sectional Data' Econometrica vol. 46, no.1, pp. 69-85.

Nakamura, A. and Nakamura, M. 1985, 'Dynamic Models of the Labor Force Behavior of Married Women Which Can be Estimated Using Limited Amounts of Past Information', Journal of Econometrics, vol. 27, no. 3, pp. 273-298.

Wooldridge, J. M. 2000, 'A Framework for Estimating Dynamic, Unobserved Effects Panel Data Models with Possible Feedback to Future Explanatory Variables', Economics Letters, vol. 68, no. 3, pp. 245-250.

Wooldridge, J. M, 2005, 'Simple Solutions to the Initial Conditions Problem in Dynamic, Nonlinear Panel Data Models with Unobserved Heterogeneity’ Journal of Applied Econometrics, vol. 20, no. 1, pp. 39-54. 
Figure 1.Simulated dynamic employment effect of birth.

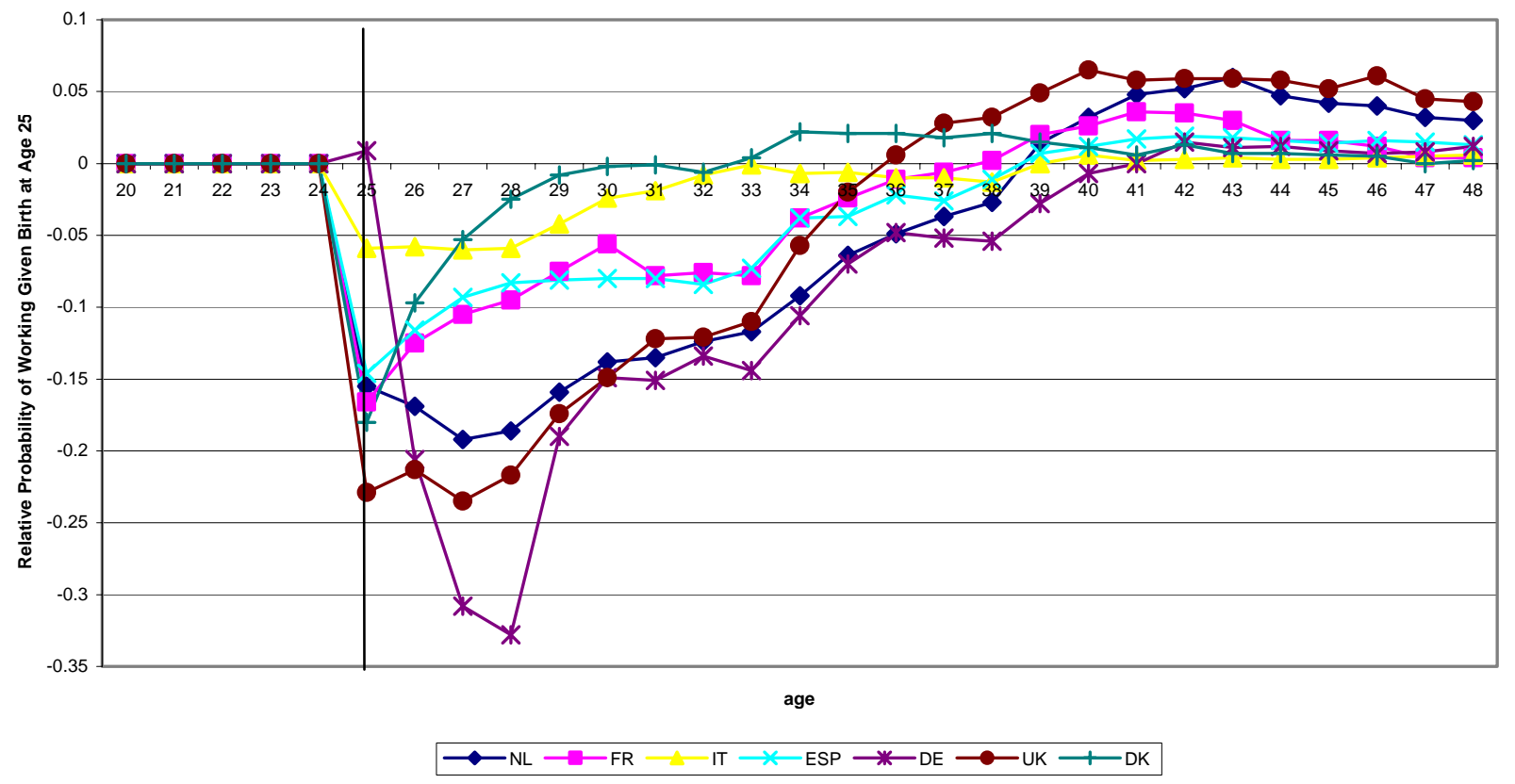

Notes: The simulation is performed in each country for a woman with average characteristics at age 20 . Employment outcomes are simulated until each woman reaches age 25 assuming no children until that age. The graph shows the relative difference in employment probabilities under two scenarios. The first when we exogenously impose a birth at age 25 and the second, the counterfactual, where a birth does not occur until after age 25. We repeat this simulation 1000 times averaging over draws of heterogeneity and time-varying shocks. 
Figure 2.Simulated cumulative effect of birth on years employed.

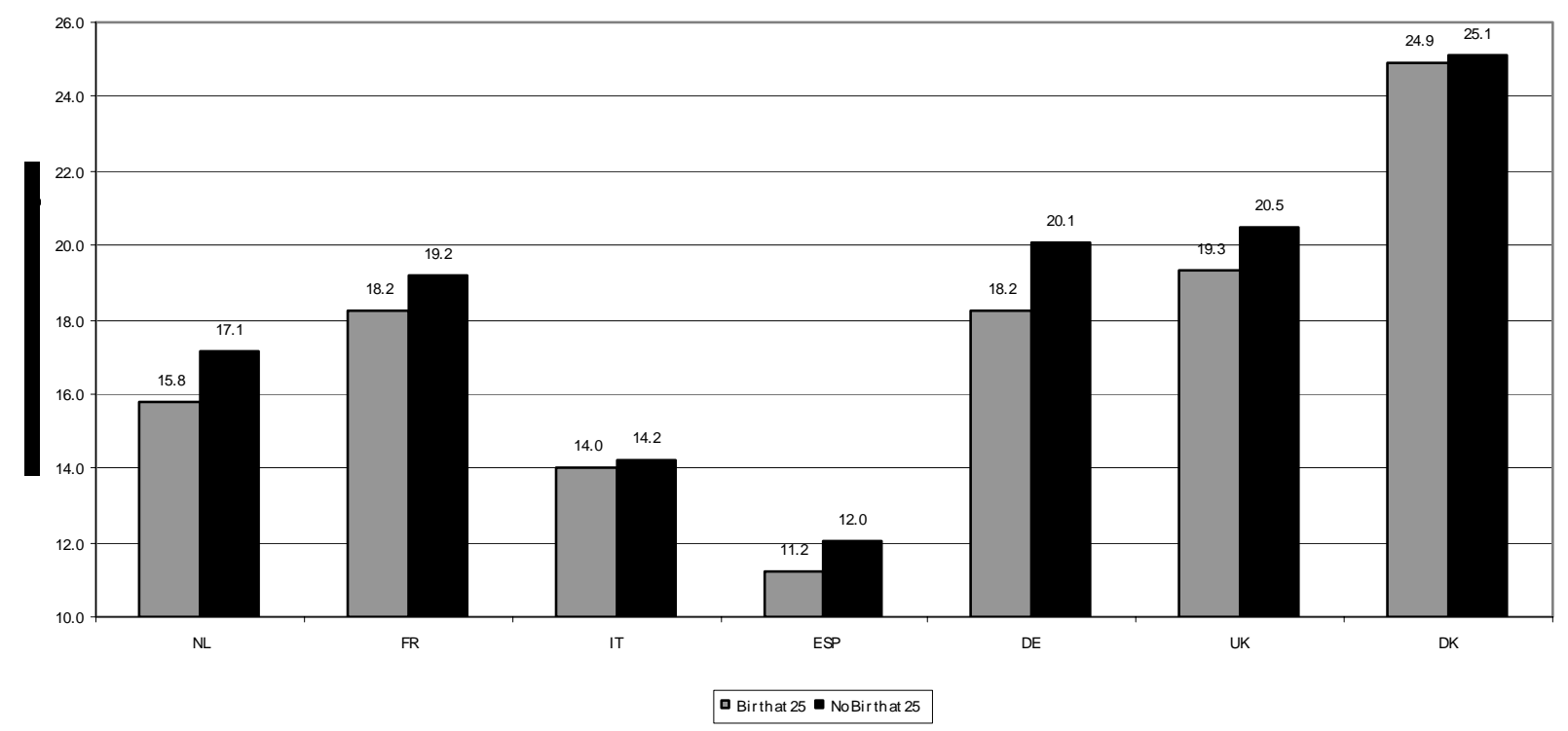

Notes: The simulation is performed in each country for a woman with average characteristics at age 20. Employment outcomes are simulated until each woman reaches age 25 assuming no children until that age. The graph shows the relative difference in employment probabilities under two scenarios: the first when we exogenously impose a birth at age 25; and the second, the counterfactual, where a birth does not occur until after age 25 . We repeat this simulation 1000 times averaging over draws of heterogeneity and time-varying shocks. 
Table 1. Maternity leave and childcare across countries.

\begin{tabular}{lccc}
\hline \hline $\begin{array}{l}\text { Maternity/ childcare } \\
\text { leave for 1999/2000 }\end{array}$ & $\begin{array}{c}\text { Duration of maternity } \\
\text { leave (weeks) }\end{array}$ & $\begin{array}{c}\text { Maternity benefits } \\
\text { (\% of average wages) }\end{array}$ & $\begin{array}{c}\text { Total duration of } \\
\text { maternity/child-care } \\
\text { leave (weeks) }\end{array}$ \\
\cline { 2 - 4 } Denmark & 30 & 100 & 82 \\
France & 16 & 100 & 162 \\
Germany & 14 & 100 & 162 \\
Italy & 21,5 & 80 & 64,5 \\
Netherlands & 16 & 100 & 68 \\
Spain & 16 & 100 & 164 \\
United Kingdom & 18 & 44 & 44 \\
\hline & & & \\
Childcare & Coverage \% (Opening hours) & \\
Denmark & $0-3$ Yrs old & $3-6$ Yrs old \\
France & $64(11)$ & $91(11)$ & \\
Germany & $29(10.2)$ & $99(8)$ & \\
Italy & $10(10)$ & $78(6.7)$ & \\
Netherlands & $6(10)$ & $95(8)$ & \\
Spain & $6(10.5)$ & $98(5.5)$ & \\
United Kingdom & $5(7)$ & $60^{\circ}(5.2)$ & \\
\hline \hline
\end{tabular}

Source: CESifo - DICE based on OECD Employment Outlook 2001, p. 144. a) The data for coverage refer to the proportion of young children using formal child-care arrangements which include both public and private provision b) England only. 
Table 2. Summary statistics by country.

Employed

Age

Low Education

Medium Education

Higher Education

Very good health

Good health

Poor health

Husband's income '000000s Euros

Employed by number of children

0

1

2

$3+$

Number of individuals

\begin{tabular}{ccccccc} 
Denmark & France & Germany & Netherlands & Italy & Spain & UK \\
\hline 0,836 & 0,631 & 0,627 & 0,558 & 0,485 & 0,388 & 0,674 \\
$(0,370)$ & $(0,483)$ & $(0,484)$ & $(0,497)$ & $(0,500)$ & $(0,487)$ & $(0,469)$ \\
36,181 & 36,908 & 36,615 & 37,012 & 37,929 & 37,549 & 36,180 \\
$(7,293)$ & $(7,152)$ & $(7,101)$ & $(6,803)$ & $(6,617)$ & $(6,766)$ & $(7,266)$ \\
0,180 & 0,306 & 0,203 & 0,217 & 0,521 & 0,620 & 0,518 \\
$(0,384)$ & $(0,461)$ & $(0,402)$ & $(0,412)$ & $(0,500)$ & $(0,485)$ & $(0,500)$ \\
0,416 & 0,435 & 0,605 & 0,597 & 0,400 & 0,186 & 0,156 \\
$(0,493)$ & $(0,496)$ & $(0,489)$ & $(0,491)$ & $(0,490)$ & $(0,389)$ & $(0,363)$ \\
0,404 & 0,259 & 0,193 & 0,186 & 0,079 & 0,194 & 0,326 \\
$(0,491)$ & $(0,438)$ & $(0,395)$ & $(0,389)$ & $(0,270)$ & $(0,395)$ & $(0,469)$ \\
0,562 & 0,151 & 0,091 & 0,188 & 0,141 & 0,192 & 0,238 \\
$(0,496)$ & $(0,358)$ & $(0,287)$ & $(0,391)$ & $(0,348)$ & $(0,394)$ & $(0,426)$ \\
0,325 & 0,542 & 0,497 & 0,620 & 0,542 & 0,612 & 0,482 \\
$(0,468)$ & $(0,498)$ & $(0,500)$ & $(0,485)$ & $(0,498)$ & $(0,487)$ & $(0,500)$ \\
0,113 & 0,306 & 0,412 & 0,192 & 0,316 & 0,196 & 0,280 \\
$(0,317)$ & $(0,461)$ & $(0,492)$ & $(0,394)$ & $(0,465)$ & $(0,397)$ & $(0,449)$ \\
0,203 & 0,196 & 0,185 & 0,186 & 0,126 & 0,115 & 0,177 \\
$(0,088)$ & $(0,191)$ & $(0,103)$ & $(0,088)$ & $(0,067)$ & $(0,078)$ & $(0,100)$ \\
& & & & & & \\
0,828 & 0,687 & 0,798 & 0,763 & 0,549 & 0,503 & 0,848 \\
0,840 & 0,715 & 0,676 & 0,568 & 0,508 & 0,388 & 0,688 \\
0,864 & 0,637 & 0,521 & 0,478 & 0,448 & 0,360 & 0,614 \\
0,826 & 0,380 & 0,326 & 0,346 & 0,356 & 0,294 & 0,447 \\
1.075 & 2.316 & 2.608 & 1.978 & 2.699 & 2.440 & 1.609 \\
\hline & & & & & &
\end{tabular}

Notes: Standard errors in parentheses. 
Table 3. Employment rates before and after birth.

\begin{tabular}{lcccccc}
\hline \hline \multirow{2}{*}{ Country } & Employment & \multicolumn{6}{c}{} \\
& rate & \multicolumn{2}{c}{ relative difference to pre-birth employment rate } \\
& pre-birth & Birth & 1 & 2 & 3 & 4 \\
\cline { 2 - 7 } Denmark & 0,910 & $-0,079$ & 0,059 & 0,122 & 0,126 & 0,159 \\
France & 0,608 & $-0,114$ & $-0,120$ & $-0,125$ & $-0,078$ & $-0,038$ \\
Germany & 0,551 & $-0,025$ & $-0,093$ & $-0,146$ & $-0,085$ & $-0,011$ \\
Netherlands & 0,600 & $-0,126$ & $-0,106$ & $-0,102$ & $-0,084$ & $-0,036$ \\
Italy & 0,426 & $-0,069$ & $-0,067$ & $-0,058$ & $-0,041$ & $-0,061$ \\
Spain & 0,370 & $-0,046$ & $-0,059$ & $-0,005$ & 0,009 & $-0,018$ \\
United Kingdom & 0,555 & $-0,070$ & $-0,039$ & $-0,040$ & $-0,004$ & 0,015 \\
\hline \hline
\end{tabular}

Note: Sample of married and cohabiting females giving birth between 1995 and 1998 and not giving birth in the subsequent 4 years. 
Table 4. Summary statistics by country.

\begin{tabular}{|c|c|c|c|c|c|c|c|}
\hline & Denmark & France & Germany & Netherlands & Italy & Spain & UK \\
\hline Less than two children & $\begin{array}{c}0.602 \\
(0.489)\end{array}$ & $\begin{array}{c}0.566 \\
(0.496)\end{array}$ & $\begin{array}{c}0.655 \\
(0.476)\end{array}$ & $\begin{array}{c}0.574 \\
(0.495)\end{array}$ & $\begin{array}{c}0.634 \\
(0.482)\end{array}$ & $\begin{array}{c}0.582 \\
(0.493)\end{array}$ & $\begin{array}{c}0.609 \\
(0.488)\end{array}$ \\
\hline Same sex for more than one chidlren & $\begin{array}{c}0.207 \\
(0.405)\end{array}$ & $\begin{array}{c}0.222 \\
(0.416)\end{array}$ & $\begin{array}{c}0.177 \\
(0.382)\end{array}$ & $\begin{array}{c}0.216 \\
(0.412)\end{array}$ & $\begin{array}{c}0.184 \\
(0.387)\end{array}$ & $\begin{array}{c}0.218 \\
(0.413)\end{array}$ & $\begin{array}{c}0.176 \\
(0.381)\end{array}$ \\
\hline Children of same sex are boys & $\begin{array}{c}0.109 \\
(0.312)\end{array}$ & $\begin{array}{c}0.120 \\
(0.325)\end{array}$ & $\begin{array}{c}0.097 \\
(0.296)\end{array}$ & $\begin{array}{c}0.111 \\
(0.314)\end{array}$ & $\begin{array}{c}0.101 \\
(0.302)\end{array}$ & $\begin{array}{c}0.119 \\
(0.324)\end{array}$ & $\begin{array}{c}0.095 \\
(0.293)\end{array}$ \\
\hline Children of same sex are girls & $\begin{array}{c}0.098 \\
(0.297)\end{array}$ & $\begin{array}{c}0.102 \\
(0.304)\end{array}$ & $\begin{array}{c}0.080 \\
(0.271)\end{array}$ & $\begin{array}{c}0.105 \\
(0.307)\end{array}$ & $\begin{array}{c}0.083 \\
(0.276)\end{array}$ & $\begin{array}{c}0.099 \\
(0.299)\end{array}$ & $\begin{array}{c}0.081 \\
(0.273)\end{array}$ \\
\hline Number of individuals & 1,075 & 2,316 & 2,608 & 1,978 & 2,699 & 2,440 & 1,609 \\
\hline
\end{tabular}


Table 5. Pooled probit birth equation by country.

\begin{tabular}{|c|c|c|c|c|c|c|c|}
\hline & Denmark & France & Germany & Netherlands & Italy & Spain & UK \\
\hline \multirow[t]{2}{*}{ Same sex for more than one children } & 0,767 & 0,729 & 0,813 & 0,792 & 0,847 & 0,904 & 0,696 \\
\hline & $(0,070)$ & $(0,047)$ & $(0,049)$ & $(0,055)$ & $(0,048)$ & $(0,054)$ & $(0,057)$ \\
\hline \multirow[t]{2}{*}{ Less than two children } & 2,899 & 2,730 & 2,885 & 3,245 & 2,891 & 3,287 & 2,686 \\
\hline & $(0,089)$ & $(0,056)$ & $(0,059)$ & $(0,070)$ & $(0,057)$ & $(0,065)$ & $(0,067)$ \\
\hline \multirow[t]{2}{*}{ Number of children aged 1-3 } & 0,740 & 0,776 & 0,987 & 0,989 & 0,752 & 0,928 & 0,943 \\
\hline & $(0,049)$ & $(0,036)$ & $(0,039)$ & $(0,041)$ & $(0,036)$ & $(0,041)$ & $(0,040)$ \\
\hline \multirow[t]{2}{*}{ Number of children aged 4-6 } & 1,176 & 0,969 & 1,009 & 1,266 & 0,821 & 1,042 & 1,036 \\
\hline & $(0,057)$ & $(0,038)$ & $(0,037)$ & $(0,043)$ & $(0,037)$ & $(0,040)$ & $(0,043)$ \\
\hline \multirow[t]{2}{*}{ Number of children aged 7-12 } & 0,899 & 0,766 & 0,916 & 0,940 & 1,029 & 1,073 & 0,740 \\
\hline & $(0,043)$ & $(0,026)$ & $(0,026)$ & $(0,030)$ & $(0,029)$ & $(0,031)$ & $(0,030)$ \\
\hline \multirow[t]{2}{*}{ Number of children aged 13-18 } & 0,778 & 0,800 & 0,922 & 0,885 & 0,960 & 1,058 & 0,786 \\
\hline & $(0,057)$ & $(0,034)$ & $(0,034)$ & $(0,041)$ & $(0,034)$ & $(0,037)$ & $(0,044)$ \\
\hline \multirow[t]{2}{*}{ Medium education } & $-0,019$ & $-0,003$ & $-0,011$ & 0,122 & 0,044 & $-0,049$ & $-0,065$ \\
\hline & $(0,066)$ & $(0,039)$ & $(0,038)$ & $(0,046)$ & $(0,031)$ & $(0,043)$ & $(0,053)$ \\
\hline \multirow[t]{2}{*}{ Higher education } & 0,018 & $-0,007$ & 0,030 & 0,241 & 0,199 & 0,047 & 0,028 \\
\hline & $(0,068)$ & $(0,044)$ & $(0,049)$ & $(0,057)$ & $(0,055)$ & $(0,043)$ & $(0,042)$ \\
\hline \multirow[t]{2}{*}{ Age } & $-0,263$ & $-0,260$ & $-0,281$ & $-0,220$ & $-0,344$ & $-0,289$ & $-0,199$ \\
\hline & $(0,026)$ & $(0,017)$ & $(0,016)$ & $(0,019)$ & $(0,016)$ & $(0,018)$ & $(0,018)$ \\
\hline \multirow[t]{2}{*}{ Good health } & $-0,089$ & $-0,148$ & $-0,093$ & $-0,060$ & $-0,071$ & $-0,029$ & $-0,031$ \\
\hline & $(0,051)$ & $(0,043)$ & $(0,049)$ & $(0,045)$ & $(0,041)$ & $(0,041)$ & $(0,045)$ \\
\hline \multirow[t]{2}{*}{ Poor health } & $-0,183$ & $-0,252$ & $-0,109$ & $-0,165$ & $-0,045$ & $-0,040$ & $-0,102$ \\
\hline & $(0,079)$ & $(0,048)$ & $(0,052)$ & $(0,059)$ & $(0,044)$ & $(0,052)$ & $(0,051)$ \\
\hline \multirow[t]{2}{*}{ Husband's income } & 0,256 & 0,146 & 0,556 & 0,326 & $-0,108$ & 0,229 & 0,344 \\
\hline & $(0,283)$ & $(0,088)$ & $(0,139)$ & $(0,216)$ & $(0,230)$ & $(0,235)$ & $(0,188)$ \\
\hline \multirow[t]{2}{*}{ Constant } & $-3,569$ & $-3,276$ & $-3,783$ & $-4,259$ & $-3,459$ & $-4,112$ & $-3,654$ \\
\hline & $(0,128)$ & $(0,087)$ & $(0,091)$ & $(0,103)$ & $(0,084)$ & $(0,091)$ & $(0,099)$ \\
\hline Log-Likelihood/N & $-1896,57$ & $-4036,54$ & $-4553,86$ & $-3075,62$ & $-4969,31$ & $-3896,99$ & $-2991,81$ \\
\hline
\end{tabular}

Notes: Point estimates with standard errors in parentheses. 
Table 6. Estimation results for employment equation with serially correlated errors and exogenous fertility.

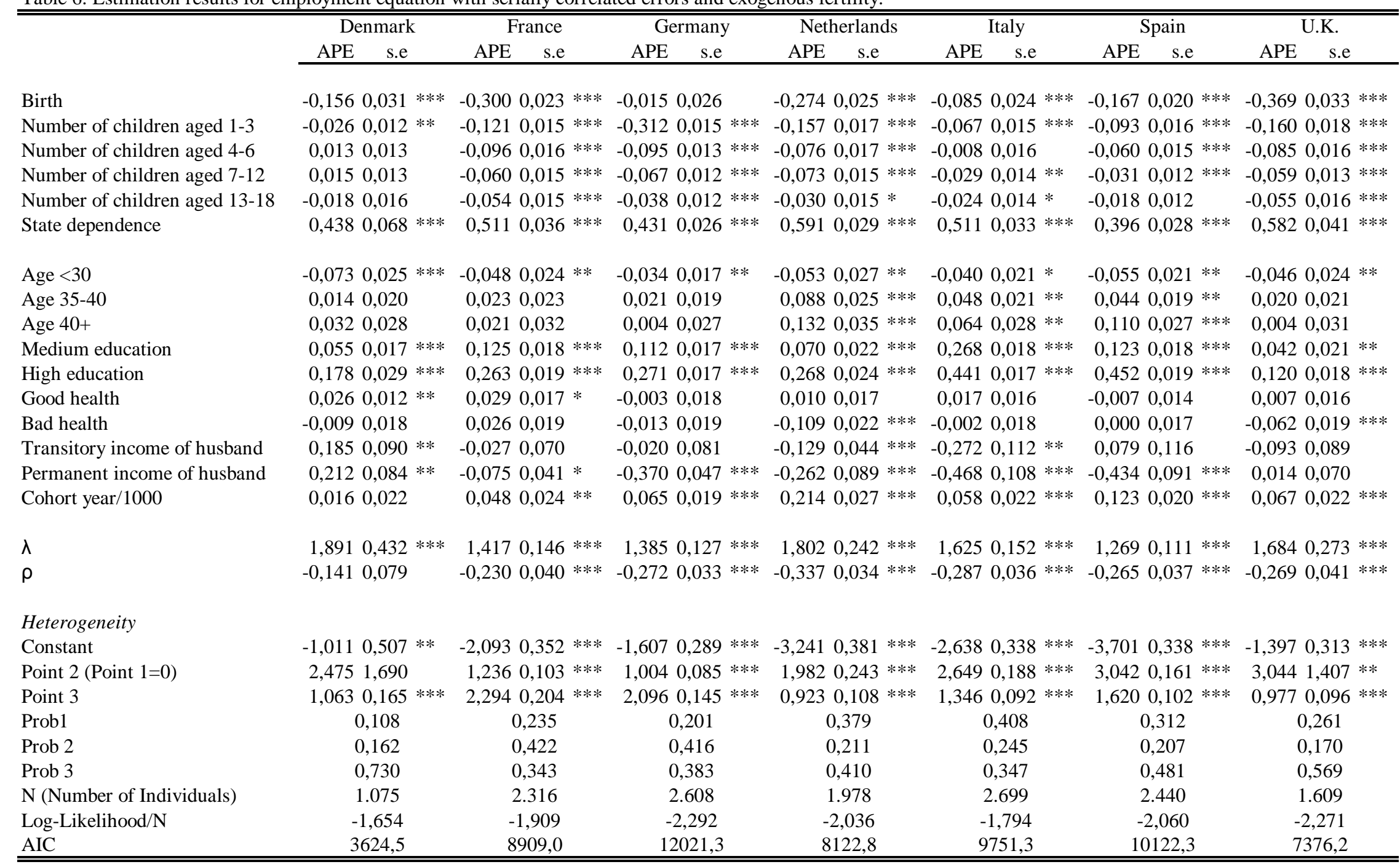

Notes: The Average partial effects (APE) are based on Maximum likelihood estimates of the employment equation implementing the Heckman initial conditions solution with serially correlated error term. APE are calculated using the numerical derivative of the predicted probability for each individual and type and then weighted and averaged over all individuals. * denotes statistical significance at the $10 \%$ level, ** at the $5 \%$ level and ${ }^{* * *}$ at the $1 \%$ level. Standard errors are calculated using Monte Carlo replications (200) from the estimated distribution of the parameters. 
Table 7. Sensitivity analysis to various assumptions - Employment equation with exogenous fertility.

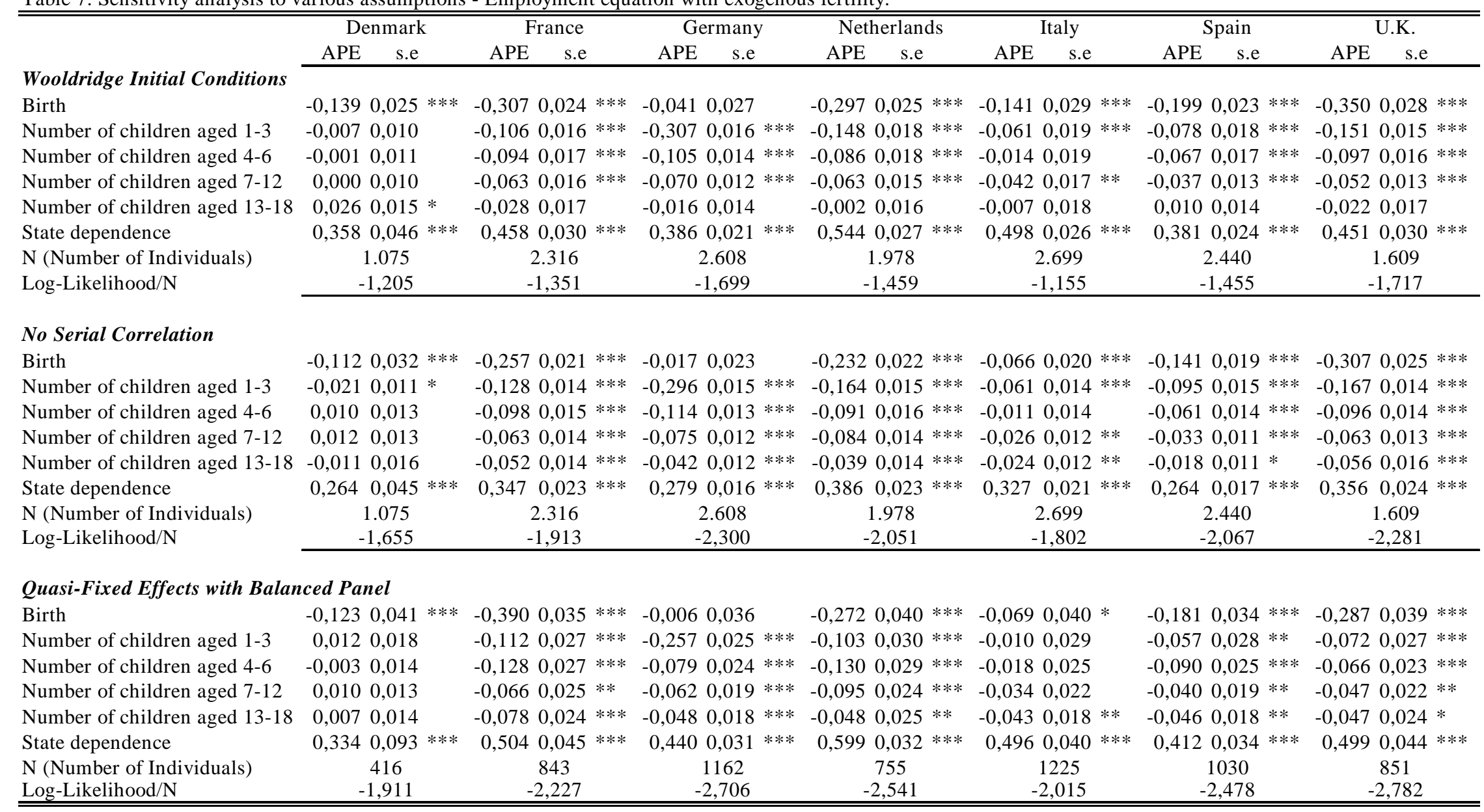

Notes: The Average partial effects (APE) are based on Maximum likelihood estimates of the employment equation implementing: 1) in the top panel, the Wooldridge initial conditions solution with serially correlated error term, 2) in the middle panel, the Heckman initial conditions solution with no serially correlated error term and 3) in the bottom panel, the Heckman initial conditions solution with serially correlated error term for a balanced panel with quais-fixed effects. APE are calculated using the numerical derivative of the predicted probability for each individual and type and then weighted and averaged over all individuals. * denotes statistical significance at the $10 \%$ level, ** at the $5 \%$ level and *** at the $1 \%$ level. Standard errors are calculated using Monte Carlo replications (200) from the estimated distribution of the parameters. 
Table 8. Results from joint estimation of employment and birth equations.

\begin{tabular}{|c|c|c|c|c|c|c|c|c|c|c|c|c|c|c|}
\hline \multirow{2}{*}{ 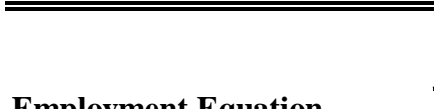 } & \multicolumn{2}{|c|}{ Denmark } & \multicolumn{2}{|c|}{ France } & \multicolumn{2}{|c|}{ Germany } & \multicolumn{2}{|c|}{ Netherlands } & \multicolumn{2}{|c|}{ Italy } & \multicolumn{2}{|c|}{ Spain } & \multicolumn{2}{|r|}{ U.K. } \\
\hline & APE & s.e & APE & s.e & $\mathrm{APE}$ & s.e & APE & s.e & APE & s.e & $\mathrm{APE}$ & s.e & $\mathrm{APE}$ & s.e \\
\hline & & & & & & & & & & & & & & \\
\hline Birth & $-0,271$ & $0,089 * * *$ & $-0,355$ & $0,057 * * *$ & $-0,052$ & $0,051 * *$ & $-0,332$ & $0,052 * * *$ & $-0,174$ & $0,045 * * *$ & $-0,251$ & $0,034 * * *$ & $-0,432$ & $0,061 * * *$ \\
\hline Less than two children & 0,013 & 0,022 & 0,066 & $0,022 * *$ & 0,012 & 0,019 & 0,060 & $0,026 * *$ & 0,023 & 0,018 & 0,037 & $0,020 *$ & $-0,010$ & 0,023 \\
\hline Number of children aged 1-3 & $-0,014$ & 0,014 & $-0,073$ & $0,014 * * *$ & $-0,275$ & $0,015 * * *$ & $-0,132$ & $0,017 * * *$ & $-0,046$ & $0,015 * * *$ & $-0,080$ & $0,016 * * *$ & $-0,140$ & $0,016 * * *$ \\
\hline Number of children aged 4-6 & 0,014 & 0,015 & $-0,029$ & $0,015 * * *$ & $-0,079$ & $0,014 * * *$ & $-0,038$ & $0,017 * *$ & 0,015 & 0,015 & $-0,040$ & $0,015 * *$ & $-0,065$ & $0,015 * * *$ \\
\hline Number of children aged 7-12 & 0,003 & 0,012 & $-0,010$ & 0,011 & $-0,059$ & $0,012 * * *$ & $-0,039$ & $0,013 * * *$ & $-0,017$ & 0,013 & $-0,025$ & $0,012 * *$ & $-0,034$ & $0,012 * * *$ \\
\hline Number of children aged 13-18 & 0,008 & 0,015 & 0,023 & 0,013 & $-0,004$ & 0,012 & 0,032 & $0,015 * *$ & 0,013 & 0,012 & 0,011 & 0,012 & 0,007 & 0,014 \\
\hline State dependence & 0,306 & $0,057 * * *$ & 0,422 & $0,033 * * *$ & 0,360 & $0,024 * * *$ & 0,494 & $0,031 * * *$ & 0,440 & $0,030 * * *$ & 0,355 & $0,026 * * *$ & 0,452 & $0,033 * * *$ \\
\hline Age $<30$ & $-0,034$ & 0,029 & $-0,019$ & 0,022 & $-0,010$ & 0,017 & $-0,017$ & 0,028 & $-0,014$ & 0,020 & $-0,037$ & $0,022 *$ & $-0,012$ & 0,024 \\
\hline Age $35-40$ & $-0,004$ & 0,022 & 0,001 & 0,022 & $-0,001$ & 0,019 & 0,049 & $0,025 * *$ & 0,030 & 0,019 & 0,038 & $0,019 * *$ & $-0,021$ & 0,021 \\
\hline Age 40+ & $-0,032$ & 0,031 & $-0,032$ & 0,031 & $-0,044$ & $0,026 *$ & 0,045 & 0,034 & 0,009 & 0,026 & 0,069 & $0,027 * *$ & $-0,085$ & $0,031 * * *$ \\
\hline Medium education & 0,046 & $0,018 * *$ & 0,158 & $0,017 * * *$ & 0,129 & $0,016 * * *$ & 0,066 & $0,020 * * *$ & 0,288 & $0,016 * * *$ & 0,140 & $0,017 * * *$ & 0,066 & $0,022 * * *$ \\
\hline High education & 0,117 & $0,032 * * *$ & 0,278 & $0,017 * * *$ & 0,272 & $0,016 * * *$ & 0,298 & $0,023 * * *$ & 0,469 & $0,015 * * *$ & 0,461 & $0,017 * * *$ & 0,143 & $0,018 * * *$ \\
\hline Good health & 0,021 & 0,013 & 0,034 & $0,016 * *$ & $-0,004$ & 0,017 & 0,003 & 0,017 & 0,014 & 0,015 & $-0,002$ & 0,014 & 0,010 & 0,016 \\
\hline Bad health & 0,008 & 0,018 & 0,030 & $0,017 *$ & $-0,008$ & 0,018 & $-0,107$ & $0,021 * * *$ & $-0,006$ & 0,016 & 0,010 & 0,017 & $-0,049$ & $0,018 * * *$ \\
\hline Transitory income of husband & 0,137 & 0,094 & $-0,022$ & 0,068 & $-0,025$ & 0,080 & $-0,113$ & $0,040 * * *$ & $-0,240$ & $0,102 * *$ & 0,118 & 0,115 & $-0,074$ & 0,088 \\
\hline Permanent income of husband & 0,193 & $0,099 * *$ & $-0,049$ & 0,043 & $-0,359$ & $0,043 * * *$ & $-0,400$ & $0,101 * * *$ & $-0,589$ & $0,103 * * *$ & $-0,266$ & $0,097 * * *$ & 0,059 & 0,077 \\
\hline Cohort year/1000 & $-0,028$ & 0,023 & $-0,014$ & 0,023 & 0,013 & 0,019 & 0,145 & $0,026 * * *$ & 0,010 & 0,020 & 0,091 & $0,021 * * *$ & $-0,006$ & 0,023 \\
\hline Constant & $-1,002$ & $0,575 *$ & $-2,758$ & $0,390 * * *$ & $-1,988$ & $0,351 * * *$ & $-3,476$ & $0,395 * * *$ & $-2,846$ & $0,346 * * *$ & $-4,207$ & $0,349 * * *$ & $-1,112$ & $0,346 * * *$ \\
\hline \multicolumn{15}{|l|}{ Birth Equation } \\
\hline Lag employment & $-0,006$ & 0,007 & $-0,005$ & $0,003 *$ & $-0,010$ & $0,003 * * *$ & 0,00002 & 0,002 & $-0,005$ & $0,002 * *$ & $-0,003$ & $0,002 *$ & $-0,016$ & $0,005 * * *$ \\
\hline Less than two children & 0,064 & $0,014 * * *$ & 0,031 & $0,007 * * *$ & 0,028 & $0,005 * * *$ & 0,055 & $0,010 * * *$ & 0,025 & $0,004 * * *$ & 0,031 & $0,006 * * *$ & 0,050 & $0,009 * * *$ \\
\hline Same sex for children & 0,008 & 0,013 & 0,012 & $0,006 * *$ & 0,014 & $0,006 * *$ & 0,007 & 0,005 & 0,010 & $0,005 *$ & 0,007 & 0,005 & 0,013 & 0,010 \\
\hline Children of same sex are boys & 0,000 & 0,015 & $-0,004$ & 0,006 & $-0,006$ & 0,005 & 0,005 & 0,008 & $-0,004$ & 0,005 & $-0,003$ & 0,005 & 0,001 & 0,011 \\
\hline Number of children aged 1-3 & 0,003 & 0,007 & $-0,003$ & 0,003 & $-0,004$ & 0,003 & 0,014 & $0,003 * * *$ & $-0,012$ & $0,002 * * *$ & $-0,006$ & $0,002 * *$ & 0,015 & $0,004 * * *$ \\
\hline Number of children aged 4-6 & 0,025 & $0,007 * * *$ & 0,004 & 0,003 & 0,006 & $0,002 * *$ & 0,019 & $0,003 * * *$ & $-0,003$ & 0,002 & 0,004 & $0,002 *$ & 0,016 & $0,004 * * *$ \\
\hline Number of children aged 7-12 & 0,003 & 0,006 & $-0,006$ & $0,003 * *$ & 0,001 & 0,002 & 0,001 & 0,002 & $-0,001$ & 0,002 & $-0,002$ & 0,002 & $-0,003$ & 0,004 \\
\hline Number of children aged 13-18 & $-0,017$ & $0,010 *$ & $-0,005$ & 0,003 & $-0,003$ & 0,003 & $-0,007$ & 0,005 & $-0,011$ & $0,003 * * *$ & $-0,008$ & $0,003 * * *$ & $-0,028$ & $0,007 * * *$ \\
\hline
\end{tabular}

\section{(CONTINUES)}




\begin{tabular}{|c|c|c|c|c|c|c|c|c|}
\hline Age $<30$ & $-0,0120,008$ & $-0,0050,003$ & $-0,0060,003 * *$ & $-0,010 \quad 0,002$ & $* * *$ & $0,0010,004$ & $-0,0030,003$ & $-0,0050,005$ \\
\hline Age $35-40$ & $-0,0090,008$ & $-0,0010,004$ & $-0,0080,003 * * *$ & $0,0010,003$ & & $-0,0020,003$ & $0,0050,003 *$ & $0,0070,005$ \\
\hline Age $40+$ & $-0,0700,016 * * *$ & $-0,0410,008 * * *$ & $-0,0260,006 * * *$ & $-0,0280,009$ & $* * *$ & $-0,0330,008 * * *$ & $-0,0200,006 * * *$ & $-0,0260,008 * * *$ \\
\hline Medium education & $0,0010,008$ & $-0,0010,003$ & $-0,0040,003$ & $0,0050,003$ & $*$ & $0,0060,002 * *$ & $-0,0020,002$ & $-0,0030,004$ \\
\hline High education & $0,0120,009$ & $0,0090,004 * * *$ & $-0,0030,003$ & $0,0150,004$ & $* * *$ & $0,0240,007 * * *$ & $0,0080,003 * * *$ & $0,0070,004 *$ \\
\hline Good health & $-0,0010,006$ & $0,0030,003$ & $0,0010,003$ & $-0,0030,002$ & & $0,0030,003$ & $0,0000,002$ & $0,0020,004$ \\
\hline Bad health & $-0,0220,008 * * *$ & $-0,0090,003 * *$ & $-0,0080,003 * * *$ & $-0,0090,002$ & $* * *$ & $-0,0040,003$ & $-0,0100,002 * * *$ & $-0,0030,004$ \\
\hline Transitory income of husband & $0,0180,053$ & $-0,0340,016$ & $-0,0270,018$ & $-0,0080,014$ & & $-0,0200,025$ & $-0,0190,020$ & $-0,0410,027$ \\
\hline Permanent income of husband & $0,0830,035 * *$ & $0,0080,012$ & $0,0680,008 * * *$ & $0,0720,015$ & $* * *$ & $0,0260,018$ & $0,0420,015 * * *$ & $0,0340,013 * * *$ \\
\hline Cohort year/1000 & $0,0340,012 * * *$ & $0,0270,005 * * *$ & $0,0290,005 * * *$ & $0,0240,005$ & $* * *$ & $0,0240,005 * * *$ & $0,0200,004 * * *$ & $0,0250,007 * * *$ \\
\hline Constant & $-2,3990,564 * * *$ & $-2,9640,424 * * *$ & $-3,4920,409 * * *$ & $-3,7750,473$ & $* * *$ & $-2,8540,392 * * *$ & $-3,3580,405 * * *$ & $-1,1120,346 * * *$ \\
\hline$\lambda$ & $1,5920,332 * * *$ & $1,0880,093 * * *$ & $1,1110,078 * * *$ & $1,2310,127$ & $* * *$ & $1,2810,098 * * *$ & $1,0510,078 * * *$ & $1,2240,151 * * *$ \\
\hline$\rho_{y}$ & $-0,090 \quad 0,075$ & $-0,1970,043 * * *$ & $-0,1810,037 * * *$ & $-0,2440,041$ & $* * *$ & $-0,2630,040 * * *$ & $-0,2060,040 * * *$ & $-0,2230,045 * * *$ \\
\hline$\rho_{v}$ & $0,1330,170$ & $0,0050,110$ & $-0,0910,097$ & $0,0030,104$ & & $0,0980,106$ & $0,1260,098$ & $0,0440,107$ \\
\hline \multicolumn{9}{|l|}{ Heterogeneity } \\
\hline Point 2 (Point 1=0) & $1,1850,159$ & $2,8940,195 * * *$ & $1,1420,154 * * *$ & $2,5840,210$ & $* * *$ & $3,1510,185 * * *$ & $3,3400,151 * * *$ & $2,3810,304 * * *$ \\
\hline Point 3 & $2,8462,138 * * *$ & $1,5620,133 * * *$ & $2,4680,191 * * *$ & $1,0960,099$ & $* * *$ & $1,5680,084 * * *$ & $1,7860,100 * * *$ & $1,0260,096 * * *$ \\
\hline Prob1 & 0,104 & 0,172 & 0,120 & 0,271 & & 0,405 & 0,316 & 0,254 \\
\hline Prob 2 & 0,725 & 0,420 & 0,381 & 0,277 & & 0,246 & 0,209 & 0,279 \\
\hline Prob 3 & 0,171 & 0,408 & 0,499 & 0,452 & & 0,349 & 0,475 & 0,467 \\
\hline N (Number of Individuals) & 1.075 & 2.316 & 2.608 & 1.978 & & 2.699 & 2.440 & 1.609 \\
\hline LogLikelihood/N & $-3,245$ & $-3,242$ & $-3,679$ & $-3,543$ & & $-3,077$ & $-3,204$ & $-3,973$ \\
\hline
\end{tabular}

Notes: The Average partial effects (APE) are based on Maximum likelihood estimates of the jointly estimated model of employment and fertility implementing the Heckman initial conditions solution with serially correlated error term. APE are calculated using the numerical derivative of the predicted probability for each individual and type and then weighted and averaged over all individuals. * denotes statistical significance at the $10 \%$ level, $* *$ at the $5 \%$ level and $* * *$ at the $1 \%$ level. Standard errors are calculated using Monte Carlo replications (200) from the estimated distribution of the parameters. 
Table A1. Additional sensitivity analysis - Employment equation with exogenous fertility.

\begin{tabular}{|c|c|c|c|c|c|c|c|}
\hline & Denmark & France & Germany & Netherlands & Italy & Spain & U.K. \\
\hline & APE s.e & APE s.e & APE s.e & APE s.e & APE s.e & APE s.e & APE s.e \\
\hline \multicolumn{8}{|l|}{2 points of support } \\
\hline Birth & $-0,1430,024 * * *$ & $-0,3730,023 * * *$ & $-0,0600,028 * *$ & $-0,3270,025 * * *$ & $-0,1600,027 * * *$ & $-0,2130,020 * * *$ & $-0,3760,027 * * *$ \\
\hline Number of children aged 1-3 & $-0,0130,010$ & $-0,1080,016 * * *$ & $-0,3170,014 * * *$ & $-0,1550,017 * * *$ & $-0,0820,018 * * *$ & $-0,0700,018 * * *$ & $-0,1280,015 * * *$ \\
\hline Number of children aged 4-6 & $0,0010,011$ & $-0,0960,016 * * *$ & $-0,0880,014 * * *$ & $-0,0780,017 * * *$ & $-0,0070,018$ & $-0,0590,017 * * *$ & $-0,0730,015 * * *$ \\
\hline Number of children aged 7-12 & $0,0050,011$ & $-0,0580,015 * * *$ & $-0,0690,012 * * *$ & $-0,0640,015 * * *$ & $-0,0300,016 *$ & $-0,0290,013 * *$ & $-0,0490,013 * * *$ \\
\hline Number of children aged 13-18 & $-0,008 \quad 0,014$ & $-0,0400,016 * *$ & $-0,0280,013 * *$ & $-0,0110,016$ & $-0,0140,016$ & $0,0030,015$ & $-0,0250,016$ \\
\hline State dependence & $0,4390,050 * * *$ & $0,6580,021 * * *$ & $0,5460,018 * * *$ & $0,7050,018 * * *$ & $0,7050,018 * * *$ & $0,6460,019 * * *$ & $0,6330,023 * * *$ \\
\hline N (Number of Individuals) & 1.075 & 2.316 & 2.608 & 1.978 & 2.699 & 2.440 & 1.609 \\
\hline Log-Likelihood/N & $-1,656$ & $-1,913$ & $-2,298$ & $-2,039$ & $-1,804$ & $-2,082$ & $-2,278$ \\
\hline AIC & 3625,3 & 8925,3 & 12052,4 & 8131,1 & 9802,3 & 10223,1 & 7393,4 \\
\hline
\end{tabular}

\section{Normal Unobserved Heterogeneity}

\begin{tabular}{|c|c|c|c|c|c|c|c|}
\hline Birth & $-0,1540,028 * * *$ & $-0,2600,032 * * *$ & $-0,0420,026 *$ & $-0,2720,029 * * *$ & $-0,0810,024 * * *$ & $-0,1600,029 * * *$ & $-0,3310,031 * * *$ \\
\hline Number of children aged 1-3 & $-0,0170,010$ & $-0,0890,018 * * *$ & $-0,2600,031 * * *$ & $-0,1440,019 * * *$ & $-0,0440,016 * * *$ & $-0,0710,018 * * *$ & $-0,1230,018 * * *$ \\
\hline Number of children aged 4-6 & $0,0170,011$ & $-0,0660,017 * * *$ & $-0,0660,015 * * *$ & $-0,0600,017 * * *$ & $0,0030,014$ & $-0,0360,017 * *$ & $-0,0670,016 * * *$ \\
\hline Number of children aged 7-12 & $-0,0110,011$ & $-0,0750,016 * * *$ & $-0,0790,013 * * *$ & $-0,0850,015 * * *$ & $-0,0500,013 * * *$ & $-0,0430,012 * * *$ & $-0,0640,014 * * *$ \\
\hline Number of children aged $13-18$ & $0,0040,014$ & $-0,0240,016$ & $-0,0160,013$ & $-0,0010,015$ & $-0,0060,012$ & $0,0120,012$ & $-0,0160,016$ \\
\hline State dependence & $0,4110,067 * * *$ & $0,5220,052 * * *$ & $0,4750,039 * * *$ & $0,6220,042 * * *$ & $0,4210,055 * * *$ & $0,4050,046 * * *$ & $0,5690,042 * * *$ \\
\hline N (Number of Individuals) & 1.075 & 2.316 & 2.608 & 1.978 & 2.699 & 2.440 & 1.609 \\
\hline Log-Likeliho & $-1,659$ & $-1,909$ & $-2,291$ & $-2,036$ & $-1,789$ & $-2,060$ & $-2,273$ \\
\hline \multicolumn{8}{|c|}{ Draws for Simulated Maximum Likelihood - 50} \\
\hline Birth & $-0,1560,031 * * *$ & $-0,3010,023 * * *$ & $-0,0150,027$ & $-0,2740,025 * * *$ & $-0,0840,024 * * *$ & $-0,1680,020 * * *$ & $-0,3630,032 * * *$ \\
\hline Number of children & $-0,0270,012 * *$ & $-0,1210,015 * * *$ & $-0,3120,015 * * *$ & $-0,1580,017 * * *$ & $-0,0670,015 * * *$ & $-0,0920,016 * * *$ & $-0,1550,017 * * *$ \\
\hline Number of children aged 4-6 & $0,0130,013$ & $-0,0960,016 * * *$ & $-0,0950,013 * * *$ & $-0,0760,017 * * *$ & $-0,0070,016$ & $-0,0600,015 * * *$ & $-0,0820,016 * * *$ \\
\hline Number of children aged 7-12 & $0,0150,013$ & $-0,0600,015 * * *$ & $-0,0670,012 * * *$ & $-0,0740,015 * * *$ & $-0,0280,014 * *$ & $-0,0310,012 * * *$ & $-0,0570,013 * * *$ \\
\hline Number of children aged $13-18$ & $-0,0180,016$ & $-0,0540,015 * * *$ & $-0,0380,012 * * *$ & $-0,0300,015 *$ & $-0,0230,014 *$ & $-0,0180,012$ & $-0,0530,016 * * *$ \\
\hline State dependence & $0,4390,068 * * *$ & $0,5170,036 * * *$ & $0,4310,026 * * *$ & $0,5910,029 * * *$ & $0,5140,032 * * *$ & $0,4090,028 * * *$ & $0,5770,040 * * *$ \\
\hline N (Number of Individuals) & 1.075 & 2.316 & 2.608 & 1.978 & 2.699 & 2.440 & 1.609 \\
\hline Log-Likelihood/N & $-1,654$ & $-1,908$ & $-2,292$ & $-2,036$ & $-1,794$ & $-2,059$ & $-2,271$ \\
\hline
\end{tabular}

Notes: The Average partial effects (APE) are based on Maximum likelihood estimates of the employment equation implementing the Heckman initial condiitons solution with serially correlated error term . APE are calculated using the numerical derivative of the predicted probability for each individual and type and then weighted and averaged over all individuals. $*$ denotes statistical significance at the $10 \%$ level, ** at the $5 \%$ level and $* * *$ at the $1 \%$ level. Standard errors are calculated using Monte Carlo replications (200) from the estimated distribution of the parameters. 